\title{
Multifocal Corneal Excimer Femtosecond Laser in situ Keratomileusis following Radial Keratotomy: A Case Report with Six Months of Follow-Up
}

\author{
Iraklis Vastardis ${ }^{a}$ Zisis Gatzioufas ${ }^{a} \quad$ Brigitte Eggspühler Pajic $^{a}$ \\ Jörg Müller ${ }^{a, b} \quad$ Bojan Pajic ${ }^{a-c}$ \\ ${ }^{a}$ Swiss Eye Research Foundation, ORASIS Eye Clinic, Reinach, Switzerland; ${ }^{\circ}$ University of \\ Novi Sad, Faculty of Physics, Novi Sad, and ${ }^{\mathrm{C}}$ Medical Faculty, Military Medical Academy, \\ University of Defense, Belgrade, Serbia
}

\section{Key Words}

Radial keratotomy · Multifocal corneal excimer femtosecond laser · Laser in situ keratomileusis

\section{Abstract}

We report the case of a 46-year-old female patient who was referred to our clinic (Orasis Eye Clinic, Reinach, Switzerland) seeking improvement of her distance and near visual acuity. Radial keratotomy (RK) was performed at a younger age on both eyes to correct $-5 \mathrm{D}$ myopia. The patient underwent a bilateral same-session multifocal corneal excimer femtosecond laser (Supracor) keratomileusis correction. We introduce a new correction approach, possibly suitable for presbyopic patients previously treated with RK, and we present several potential novel advantages such as enhanced near, intermediate vision, and improvement in quality of life. This is the first report of a bilateral excimer laser treatment attempt of presbyopia following RK.

(c) 2014 S. Karger AG, Basel

\section{Introduction}

Laser in situ keratomileusis (LASIK) is an effective procedure and the surgery of choice in the management of refractive errors. Over the years, LASIK has been proven to be safe, showing high efficacy and predictability, rapid visual recovery and minimal risk of complica- 
tions. Prior to the advent of excimer laser, radial keratotomy (RK) was widely performed to correct myopic refractive errors [1]. However, RK was not as predictable as LASIK, giving rise to various complications such as undercorrection or overcorrection, unstable vision and late hyperopic shift [1-3]. Post-RK correction of refractive errors includes the use of spectacles, fitting of contact lenses, photorefractive keratectomy, piggyback intraocular lenses and LASIK [4-8]. We used a new presbyLasik algorithm that performs an aspheric treatment. It differs from previous central or peripheral presbyLasik profiles because no transitional zones are created. Rather, near vision is restored by creating an elevation within the 3-mm zone, displaying a central depression (fig. 1). This modification increases total positive spherical aberrations and the depth of field [9]. Far vision correction is made between the 3.0- and 6.0-mm zone. We report the uncorrected distance visual acuity (UDVA), uncorrected near visual acuity (UNVA), uncorrected intermediate visual acuity (UIVA), higher order aberrations (Z400, Z311) and patient's satisfaction over a follow-up period of 6 months.

\section{Case Report}

A female presbyopic patient was referred to our clinic. At a younger age, RK was performed on both eyes due to high myopia. She reported glares and halos and various limitations in her daily activities. We proceeded with a presbyLasik correctional approach treating hyperopia and presbyopia in one session. Simulation with multifocal corneal contact lenses for 1 week was performed to rule out a possible visual intolerance and to estimate the refractive outcome. Scheduled eye exams took place on the 1st day, 1st week, 1st month, 3rd month and 6th month after surgery. Corneal topography and wavefront aberrometry were performed using Scheimpflug imaging and Hartmann-Shack aberrometry. Monocular visual outcomes of UDVA, UNVA, corrected distance visual acuity (CDVA) and UIVA were performed using logMar and Snellen charts. UNVA was measured at a distance of $40 \mathrm{~cm}$ and UIVA at $80 \mathrm{~cm}$ using the Logarithmic Visual Acuity Chart 2000 'New ETDRS'. Results are reported in a 20/20 scale. During the follow-up sessions, we performed a basic routine survey on a scale from 1 to 5 . It addressed four specific questions: foreign body sensation, driving, computer and reading experience without spectacles. Flap was created with the Fs laser at $9.0 \mathrm{~mm}$ and flap thickness target was $110 \mu \mathrm{m}$. Corneal ablation was performed with Technolas 217z. One-sample $t$ test was performed for 12 samples. For one-sample $t$ test, the baseline values were used as reference value of comparison. Statistical significance was defined as $\mathrm{p}<0.05$.

\section{Results}

Baseline manifest refraction spherical equivalent (MRSE) of $+1.75 \mathrm{D}$ on the right eye and $+0.75 \mathrm{D}$ on the left eye shifted to myopia on both eyes (mean $-0.4 \pm 1.16 \mathrm{D}$ ). UNVA improved significantly. UIVA improved from 20/32 on the right eye and 20/25 on the left eye to 20/25 at 6 months on both eyes. The improvement of UNVA and UIVA was statistically important (one-sample $t$ test, $p=0.0007$ and $p=0.0018$, respectively; fig. 2). CDVA improved from $20 / 32$ in both eyes at baseline to $20 / 20$ on the right eye and $20 / 25$ on the left eye at 6 months (paired sample t test, $\mathrm{p}=0.0143$; fig. 2). UDVA at baseline was 20/50 on the right eye and 20/40 on the left eye and remained stable (one-sample $t$ test, $p=0.11$, mean $0.48 \pm$ 0.17). CDVA was better in comparison to the UDVA (fig. 2). Z 400 was induced on both eyes 
and changed from +0.76 to $+0.99 \mu \mathrm{m}$ in the right eye and from +0.45 to $+0.67 \mu \mathrm{m}$ in the left eye. Z 311 changed from -0.64 to $-0.18 \mu \mathrm{m}$ in the right eye and from -0.18 to $-0.3 \mu \mathrm{m}$ in the left eye (fig. 3). Corneal $Q$ factor on $30^{\circ}$ changed from 2.40 to 1.98 in the right eye and from 1.89 to 1.56 in the left eye. Our patient gave positive scores on the survey regarding her driving, reading and PC working experience after the treatment (one-sample t test, $3.16 \pm$ $0.9, p=0.03,3.5 \pm 1.3, p=0.04$ and $3.3 \pm 1.03, p=0.02$, respectively; fig. 2 ) but gave negative scores regarding foreign body sensations $(p=0.02,2.66 \pm 1.96)$.

\section{Discussion}

RK was the treatment of choice for treating myopia in the 80's [1]. However, it has been proven to give rise to various complications, mostly unstable vision and hyperopic shift of MRSE [1-3]. After LASIK was introduced and established as the treatment of choice, refractive errors after RK were commonly treated in this manner [4-8]. Although LASIK is regarded as a good surgical option following RK, various complications like splitting of the incisions up to the center of the cornea during flap lifting are reported [10]. In our case, we considered it a relative safe approach for our patient. Given the fact that during the RK procedure, a clear zone of 3-4 $\mathrm{mm}$ is left behind and that Supracor creates the elevation within the 3-mm zone, we decided to treat presbyopia as well. In the results section, we described the refractive outcome of this approach. LASIK results after RK regarding the UDVA are well documented $[4,7,8]$. Supracor significantly improved the UIVA and UNVA. It can be debated that this improvement is due to myopic shift of the MRSE, still monovision cannot be achieved with $-0.5 \mathrm{D}$, while further myopia would clearly have a negative effect on UDVA. Induced aberrations can increase the depth of field and improve near vision [11-13]. Our patient gave positive scores regarding her daily activities and stated to be almost spectacles free. A direct comparison using the same treatment approach as we did was not possible. Regarding Supracor itself, a similar improvement of UNVA is reported [9-14]. Other reports of presbyopia treatments using corneal inlays reported good results in UNVA and UDVA and suggested that manipulation within the 3.0-mm clear zone with the Fs Laser is safe [15]. In conclusion, we would like to introduce a new correction approach for post-RK presbyopic patients that improves UNVA, UIVA and quality of life. UDVA remained stable and CDVA was better after treatment. In our patient, it was efficient and safe (fig. 1; fig. 3), and although results seem promising, applying multifocal profiles on an already aberrated cornea can result in a disaster. A simulation with multifocal corneal contact lenses prior to surgery is mandatory, and the instability of the cornea after RK has to be taken seriously under consideration before proceeding [12]. Prospective studies should be carried out in order to evaluate safety and efficacy of presbyLasik treatments following RK.

\section{Disclosure Statement}

Neither author has a financial or proprietary interest in any material or method described. 
Vastardis et al.: Multifocal Corneal Excimer Femtosecond Laser in situ Keratomileusis following Radial Keratotomy: A Case Report with Six Months of Follow-Up

\section{References}

1 Waring GO 3rd, Lynn MJ, McDonnell PJ: Results of the prospective evaluation of radial keratotomy (PERK) study 10 years after surgery. Arch Ophthalmol 1994;112:1298-1308.

2 Bullimore MA, Sheedy JE, Owen D: Diurnal visual changes in radial keratotomy: implications for visual standards. Refractive Surgery Study Group. Optom Vis Sci 1994;71:516-521.

3 McDonnell PJ, Nizam A, Lynn MJ, Waring GO 3rd: Morning-to-evening change in refraction, corneal curvature, and visual acuity 11 years after radial keratotomy in the prospective evaluation of radial keratotomy study. The PERK Study Group. Ophthalmology 1996;103:233-239.

-4 Shah SB, Lingua RW, Kim CH, Peters NT: Laser in situ keratomileusis to correct residual myopia and astigmatism after radial keratotomy. J Cataract Refract Surg 2000;26:1152-1157.

5 Kamiya K, Shimizu K: Implantable Collamer lens for hyperopia after radial keratotomy. J Cataract Refract Surg 2008;34:1403-1404.

-6 Ferreira TB, Marques EF, Filipe HP: Combined corneal collagen crosslinking and secondary intraocular lens implantation for keratectasia after radial keratotomy. J Cataract Refract Surg 2014;40:143-147.

7 Oral D, Awwad ST, Seward MS, Bowman RW, McCulley JP, Cavanagh HD: Hyperopic laser in situ keratomileusis in eyes with previous radial keratotomy. J Cataract Refract Surg 2005;31:1561-1568.

8 Lipshitz I, Man 0, Shemesh G, Lazar M, Loewenstein A: Laser in situ keratomileusis to correct hyperopic shift after radial keratotomy. J Cataract Refract Surg 2001;27:273-276.

-9 Ryan A, O'Keefe M: Corneal approach to hyperopic presbyopia treatment: six-month outcomes of a new multifocal excimer laser in situ keratomileusis procedure. J Cataract Refract Surg 2013;39:1226-1233.

$\checkmark 10$ Perente I, Utine CA, Cakir H, Yilmaz OF: Complicated flap creation with femtosecond laser after radial keratotomy. Cornea 2007;26:1138-1140.

11 Alio J, Amparo F, Ortiz D, Moreno L: Corneal multifocality with the excimer laser for presbyopia correction. Curr Opin Ophthalmol 2009;20:264-271.

12 Amigó A, Bonaque-González S: Q Factor Presbylasik. Fundamentals and therapeutic approach. J Emmetropia 2012;3:167-171.

13 Khalifa MA, Allam WA, Khalifa AM: Improving near vision in presbyopic eyes by selective treatment of highorder aberrations. Clin Ophthalmol 2011;5:1525-1530.

14 Cosar CB, Sener AB: Supracor hyperopia and presbyopia correction: 6-month results. Eur J Ophthalmol 2014;24:325-329.

15 Huseynova T, Kanamori T, Waring GO 4th, Tomita M: Small-aperture corneal inlay in patients with prior radial keratotomy surgeries. Clin Ophthalmol 2013;7:1937-1940.

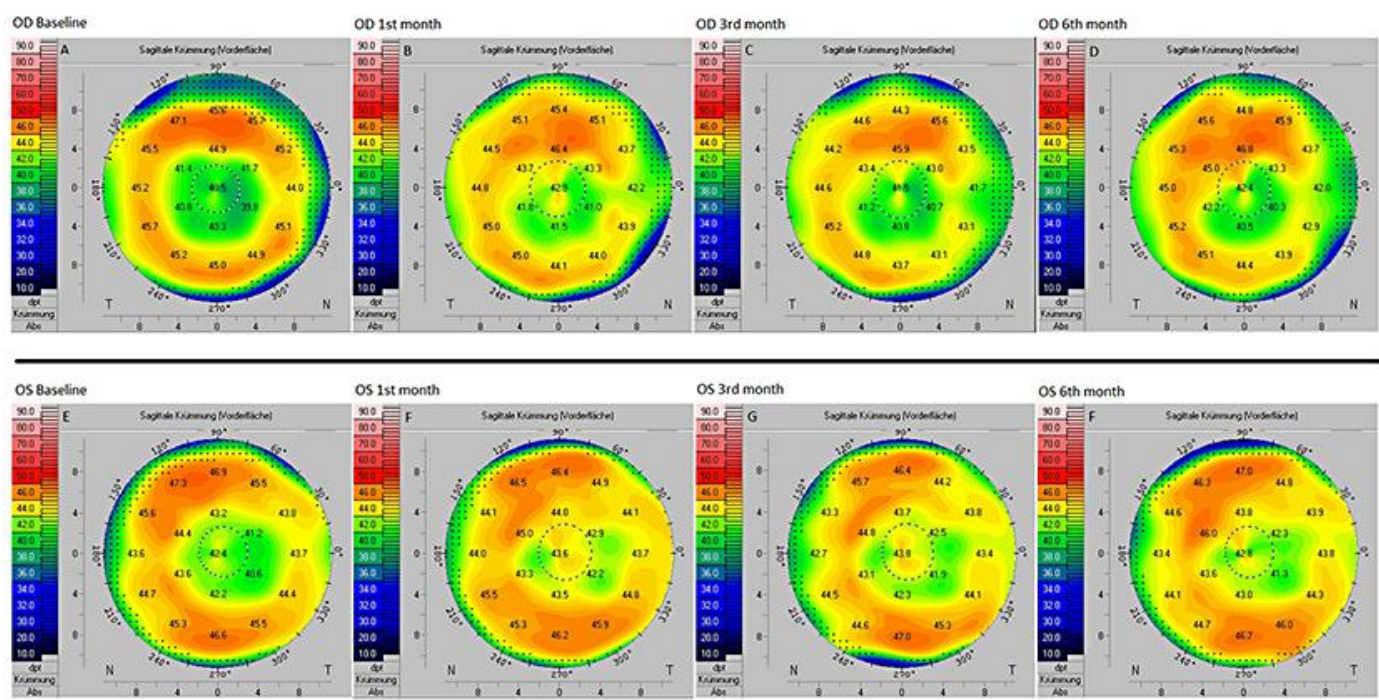

Fig. 1. Scheimpflug corneal topography through all follow-ups displaying elevation within the 3-mm zone. 


\section{Case Reports in \\ Ophthalmology}

\begin{tabular}{l|l}
\hline Case Rep Ophthalmol 2014;5:423-428 \\
\hline DOI: 10.1159/000369920 & $\begin{array}{l}\text { @ 2014 S. Karger AG, Basel } \\
\text { www.karger.com/cop }\end{array}$ \\
\hline
\end{tabular}

Vastardis et al.: Multifocal Corneal Excimer Femtosecond Laser in situ Keratomileusis following Radial Keratotomy: A Case Report with Six Months of Follow-Up

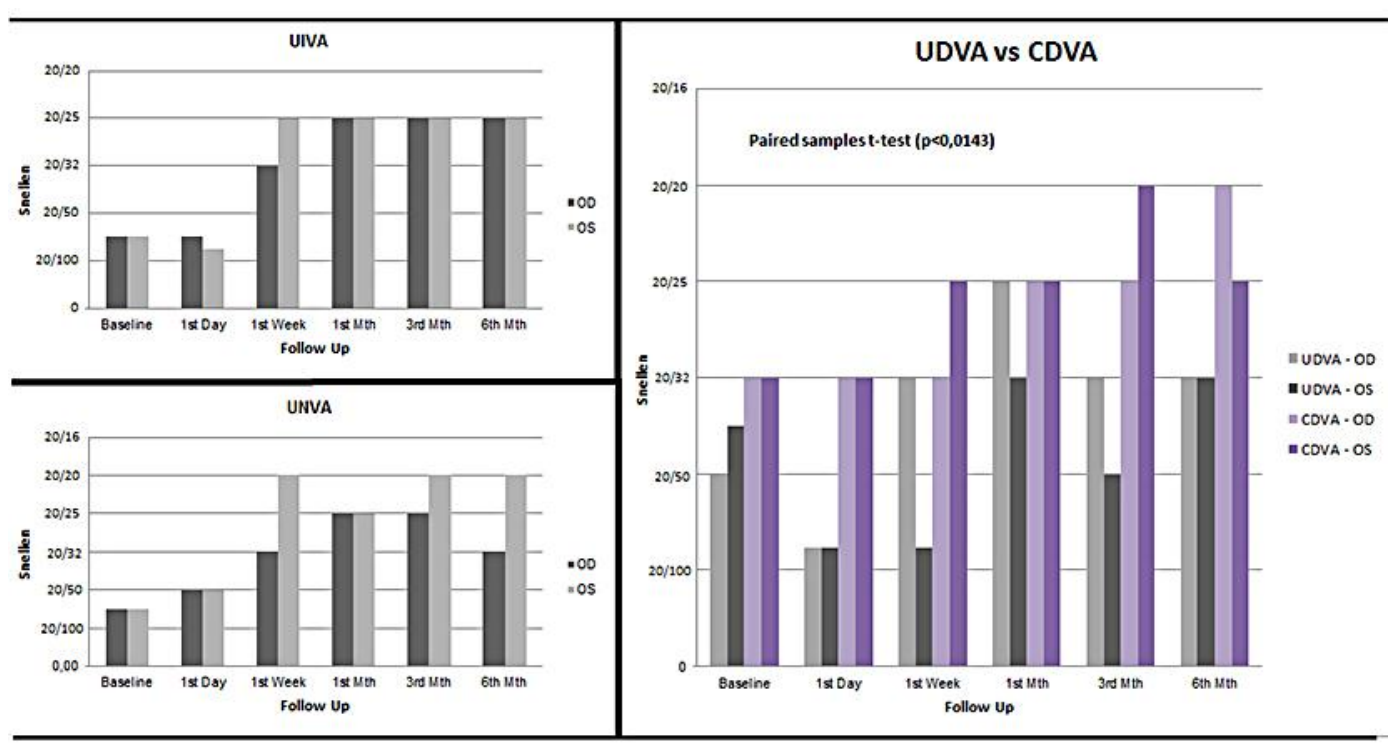

Daily activities scores

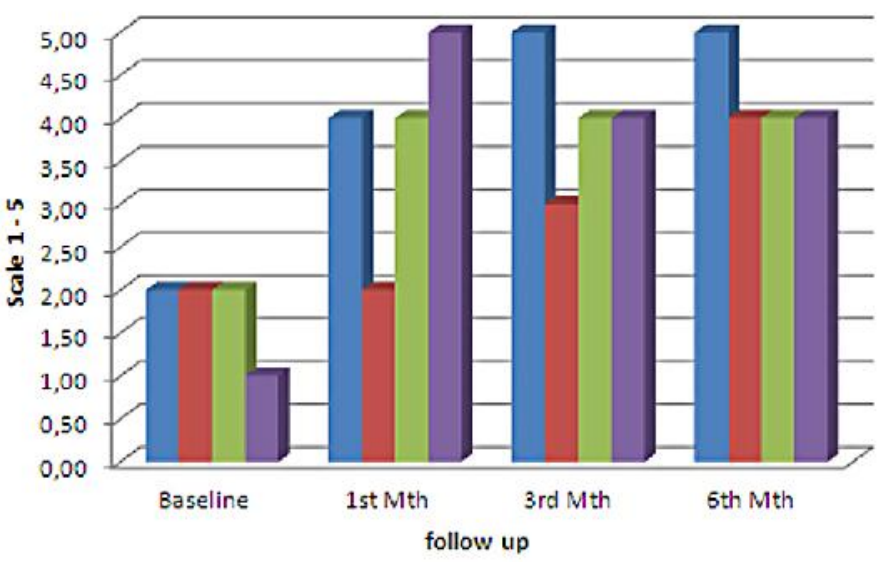

near reading experience

a Driving experience

a Computer working experience

v Foreign body sensation

Fig. 2. Visual outcomes of UIVA, UNVA and UDVA versus CDVA and scores provided from the patient regarding her daily activities (near reading, driving and computer working experience) and foreign body sensations, after Supracor corneal enhancement. Comparison of daily activities with baseline scores (onesample t test, $3.16 \pm 0.9, \mathrm{p}=0.03,3.5 \pm 1.3, \mathrm{p}=0.04,3.3 \pm 1.03, \mathrm{p}=0.02$ and $2.66 \pm 1.96, \mathrm{p}=0.02$, respectively). 
Case Reports in

Ophthalmology

\begin{tabular}{l|l}
\hline Case Rep Ophthalmol 2014;5:423-428 \\
\hline DOI: 10.1159/000369920 & $\begin{array}{l}\text { @ 2014 S. Karger AG, Basel } \\
\text { www.karger.com/cop }\end{array}$ \\
\hline
\end{tabular}

Vastardis et al.: Multifocal Corneal Excimer Femtosecond Laser in situ Keratomileusis following Radial Keratotomy: A Case Report with Six Months of Follow-Up
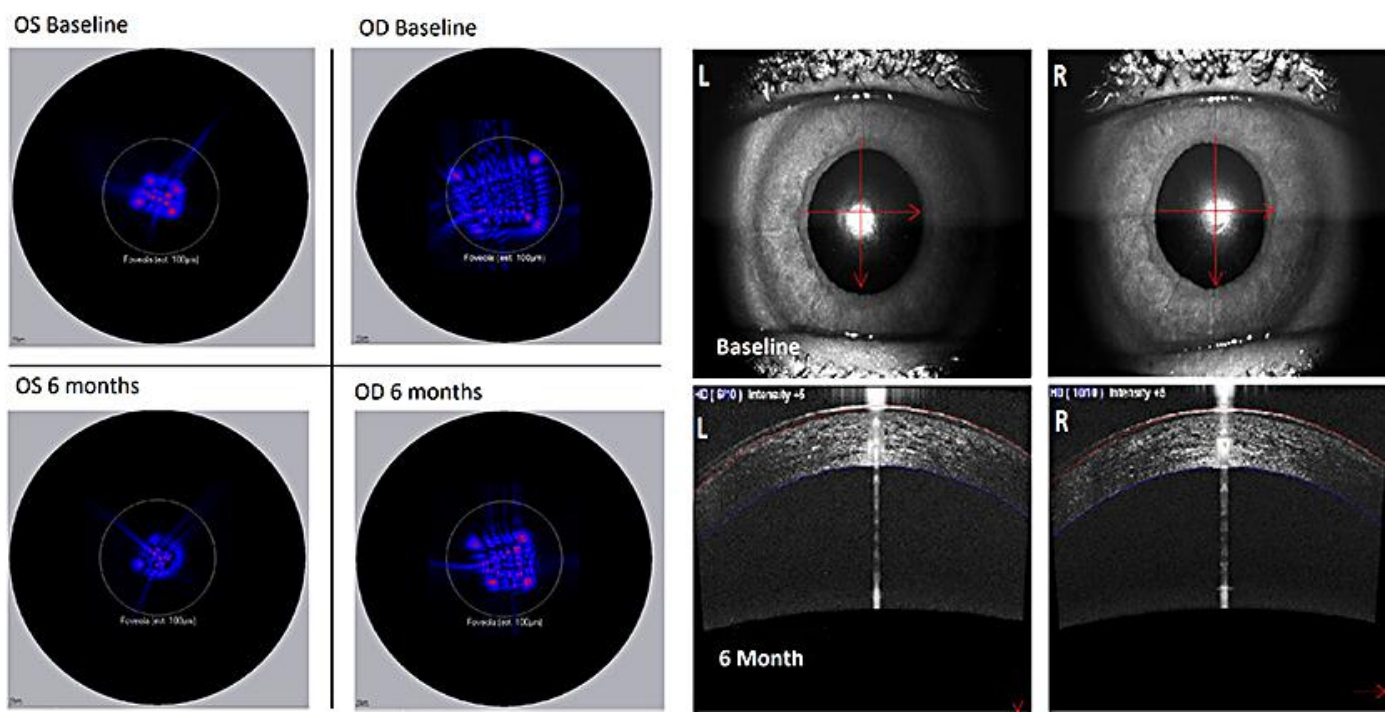

Fig. 3. Change of point spread function in fovea at baseline and at 6 months, and anterior segment OCT of both eyes at 6 months after Supracor. 